\title{
Overcoming Increasing Morbid Obesity in Korea
}

\author{
Youn Huh", ${ }^{1,2}$ Ga Eun Nam ${ }^{2,3, *}$ \\ 'Department of Family Medicine, Uijeongbu Eulji Medical Center, Eulji University, Uijeongbu; ${ }^{2}$ Committee of \\ the Health Insurance and Legislation, the Korean Society for the Study of Obesity, Seoul, ${ }^{3}$ Department of \\ Family Medicine, Korea University College of Medicine, Seoul, Korea
}

\author{
Received May 7, 202 \\ Reviewed June 12, 2021 \\ Accepted June 13, 2021 \\ *Corresponding author \\ Ga Eun Nam \\ https://orcid.org/0000-0002-6739-9904 \\ Department of Family Medicine, \\ Korea University Anam Hospital, \\ Korea University College of Medicine, \\ 73 Goryeodae-ro, Seongbuk-gu, \\ Seoul 02841, Korea \\ Tel: +82-2-920-5104 \\ Fax: +82-2-928-8083 \\ E-mail: namgaaa@daum.net
}

Obesity is a multifactorial chronic disease that has a substantial impact on patient health and on society. ${ }^{1}$ Body mass index (BMI) is a commonly used diagnostic tool for obesity, with a BMI of 25.0$29.9 \mathrm{~kg} / \mathrm{m}^{2}$ defined as overweight and $\geq 30.0 \mathrm{~kg} / \mathrm{m}^{2}$ as obesity in western countries. ${ }^{1}$ Among patients with obesity in these countries, individuals with BMI of $30.0-34.9 \mathrm{~kg} / \mathrm{m}^{2}, 35.0-39.9 \mathrm{~kg} / \mathrm{m}^{2}, 40.0-$ $49.9 \mathrm{~kg} / \mathrm{m}^{2}, 50.0-59.9 \mathrm{~kg} / \mathrm{m}^{2}$, and $\geq 60.0 \mathrm{~kg} / \mathrm{m}^{2}$ are categorized as having class I, class II, class III, class IV, and class V obesity and the latter three are classified as morbid obesity. ${ }^{1}$ The BMI cutoff for obesity in Asians is $\geq 25 \mathrm{~kg} / \mathrm{m}^{2}$ and the Korean Society for the Study of Obesity (KSSO) categorizes a BMI of $25.0-29.9 \mathrm{~kg} / \mathrm{m}^{2}, 30.0-$ $34.9 \mathrm{~kg} / \mathrm{m}^{2}, \geq 35.0 \mathrm{~kg} / \mathrm{m}^{2}$ as class I, II, and III obesity, respectively. ${ }^{2}$

Obesity is associated with chronic diseases including metabolic disorders, cardiovascular diseases, obstructive sleep apnea, and certain cancers. ${ }^{1,2}$ The disease burden may escalate as the degree of obesity increases and morbid obesity explicitly increases the risk of such comorbidities. Type 2 diabetes mellitus is highly prevalent in morbid obesity and patients with class III obesity account for $15.5 \%$ of newly-diagnosed type 2 diabetes mellitus. ${ }^{3}$ One study found that the mortality risk from cancer increased 1.5 times for men and 1.6 times for women with morbid obesity compared to normal BMI. ${ }^{4}$ The risk of diseases such as ischemic stroke, heart failure, and chronic kidney disease is increased in morbid obesity compared to normal body weight..$^{5-7}$ Morbid obesity significantly increases the risk of all-cause death compared to normal BMI and, moreover, morbid obesity shortens life expectancy by more than 5 years both in men and women. ${ }^{8}$

Despite many efforts to address the obesity epidemic, it continues to grow at an alarming rate worldwide. A notable aspect of recent obesity epidemiology is the increasing trend in morbid obesity. In several developed countries, the prevalence of morbid obesity has been reported to quadruple as the obesity prevalence doubled. ${ }^{9}$ This trend has also been reported in South Korea; an article by Nam et al. ${ }^{2}$ in this issue reported that the overall prevalence of obesity has increased during recent years and, moreover, the prevalence of class II and III obesity has also significantly increased in the population as a whole as well as nearly all age and sex groups based on the 2020 Obesity Fact Sheet by KSSO. ${ }^{2}$

When considering the impact of morbid obesity, the importance of prevention and treatment cannot be overemphasized. Particularly in morbid obesity, evaluation of causes and comorbidities is very important, because there is a very high probability that a comorbid 
disease already exists and treatment options may be limited due to pre-existing conditions. It is crucial to overcome morbid obesity through the identification of the best therapeutic strategies from comprehensive medical assessment. Pharmacologic therapy and bariatric surgery are generally considered for patients with morbid obesity beyond treatment based on diet, physical activity, and behavior. Recently, the efficacy and safely of long-term pharmacotherapy for obesity has been reported. Significant loss of body weight, maintenance of reduced weight, and improvement in comorbidities are expected to result from long-term pharmacotherapy in patients with morbid obesity. In a randomized trial comparing combined therapy with dietary interventions and lipase inhibitor to dietary intervention alone, the combined therapy resulted in a more than $30 \%$ reduction in the incidence of diabetes mellitus over 4 years of follow-up. ${ }^{10}$ Obese patients who underwent metabolic and bariatric surgery were followed for 10 years, and compared to traditionally managed obese patients, the surgery group lost significantly more weight and maintained that weight loss throughout the follow-up period; this weight change was accompanied by a significantly lower incidence of metabolic disorders such as high blood glucose and dyslipidemia. ${ }^{11}$ The 2020 KSSO Guideline for the Management of Obesity and the article based on this guideline in this issue by Kim et al. ${ }^{12}$ cover obesity treatment including diet, exercise, behavior, medicine, and bariatric surgery and suggest very useful strategies for the management of morbid obesity.
In several countries in the Organization for Economic Co-Operation and Development (OECD), socioeconomic status defined by household income or education showed an inverse association with obesity prevalence and this association was more prominent in women. ${ }^{13}$ In South Korea, the prevalence of obesity among the adult population and particularly among women increased as household income decreased based on the 2019 Obesity Fact Sheet by KSSO. ${ }^{14}$ In addition, the prevalence of obesity increased as education level decreased, predominantly in women. ${ }^{14}$ The cost of obesity management may be a key factor in the treatment rate of morbid obesity and a main issue, particularly for patients in a low socioeconomic status. Therefore, social support for obesity management is essential.

Since January 2019, metabolic and bariatric surgery and perioperative multidisciplinary care have finally been covered and reimbursed by the National Health Insurance System of South Korea. The indications for national insurance coverage are patients with a $\mathrm{BMI} \geq 35.0 \mathrm{~kg} / \mathrm{m}^{2}$ or $\mathrm{BMI} \geq 30.0 \mathrm{~kg} / \mathrm{m}^{2}$ with comorbidities such as type 2 diabetes mellitus and hypertension. After public medical insurance coverage, demand for metabolic and bariatric surgery have been rising steeply; the number of patients who underwent surgery in South Korea in 2018 before insurance coverage was 572; however, this increased by about 4.4 times to 2,529 in 2019 after coverage according to statistics from the Korean Society for Metabolic and Bariatric Surgery (Fig. 1). ${ }^{15}$ Nevertheless, patients who

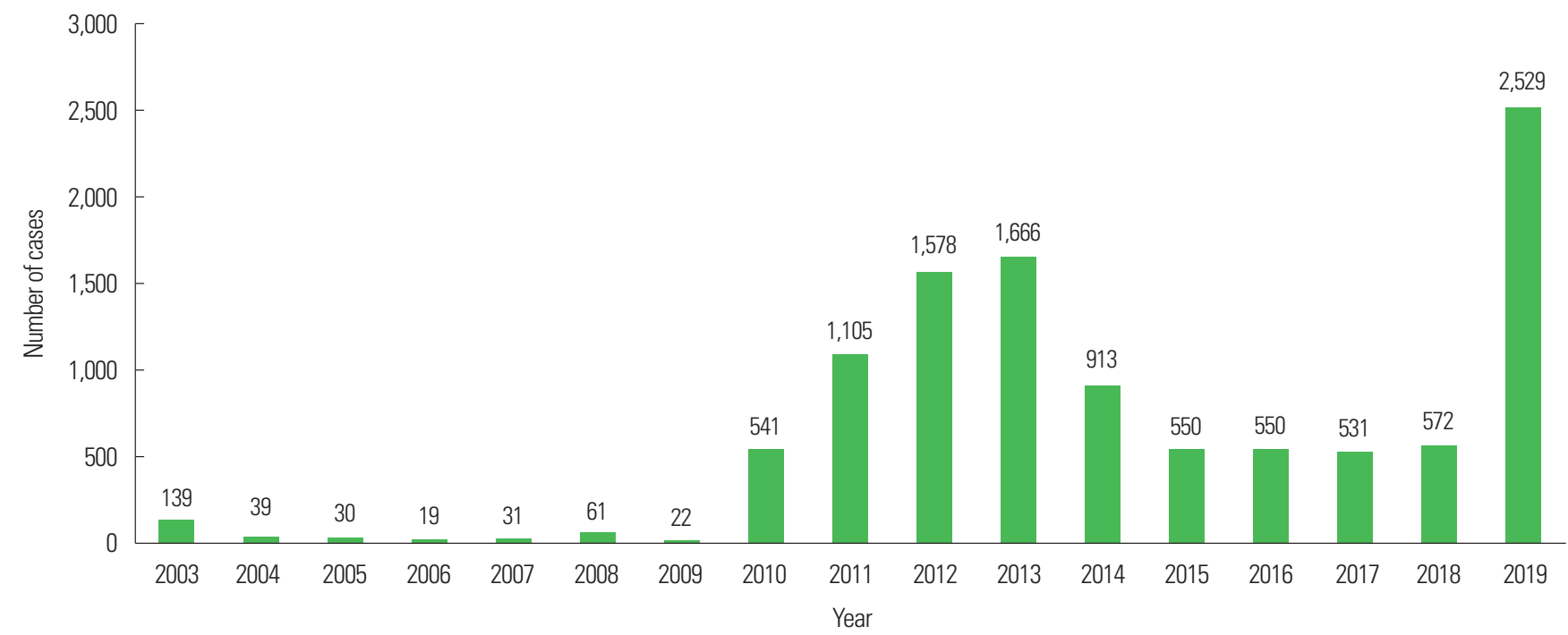

Figure 1. Annual number of bariatric and metabolic surgery in South Korea from 2003 to 2019. 
undergo metabolic and bariatric surgery are only in a fraction of all patients with morbid obesity. Moreover, other strategies for treatment for morbid obesity such as diet, exercise, behavior, and medication are not covered by health insurance benefits. Therefore, even if patients with morbid obesity undergo metabolic and bariatric surgery under the national insurance benefit, significant economic burdens are still imposed on them by the need for continuous medical therapy post-surgery as well as preoperative. This may result in discontinuation of treatment.

The indications for insurance reimbursement coverage for metabolic and bariatric surgery are consistent with the evidence-based indications. In contrast, the evidence-based and national healthcare coverage-based guidelines for standard pharmacotherapy for morbidly obese patients differ. Moreover, such medication is not covered by the Korean National Health Insurance System. Expanded application of insurance coverage for the treatment of morbid obesity and postoperative management would not only improve current health status among the morbidly obese, but would also prevent discontinuation of treatment due to economic reasons.

Obesity is a highly prevalent chronic disease and the prevalence of morbid obesity as well as overall obesity is increasing in South Korea. Morbid obesity is associated with higher risk of many chronic diseases and mortality. Multifaceted efforts by researchers and clinicians, as well as social support for the prevention and treatment of obesity are very important in overcoming the current morbid obesity epidemic.

\section{CONFLICTS OF INTEREST}

Ga Eun Nam has worked as an Associate Editor of the journal since 2020. However, she was not involved in the peer reviewer selection, evaluation, or decision process of this article. Otherwise, no other potential conflicts of interest relevant to this article were reported.

\section{AUTHOR CONTRIBUTIONS}

Study concept: GEN; drafting of the manuscript: all authors; critical revision of the manuscript: all authors; study supervision: GEN.

\section{REFERENCES}

1. Poirier P, Alpert MA, Fleisher LA, Thompson PD, Sugerman HJ, Burke LE, et al. Cardiovascular evaluation and management of severely obese patients undergoing surgery: a science advisory from the American Heart Association. Circulation 2009; 120:86-95.

2. Nam GE, Kim YH, Han K, Jung JH, Rhee EJ, Lee WY. Obesity fact sheet in Korea, 2020: prevalence of obesity by obesity class from 2009 to 2018. J Obes Metab Syndr 2021;30: 141-8.

3. Vinciguerra F, Baratta R, Farina MG, Tita P, Padova G, Vigneri R, et al. Very severely obese patients have a high prevalence of type 2 diabetes mellitus and cardiovascular disease. Acta Diabetol 2013;50:443-9.

4. Calle EE, Rodriguez C, Walker-Thurmond K, Thun MJ. Overweight, obesity, and mortality from cancer in a prospectively studied cohort of U.S. adults. N Engl J Med 2003;348:1625-38.

5. Jood K, Jern C, Wilhelmsen L, Rosengren A. Body mass index in mid-life is associated with a first stroke in men: a prospective population study over 28 years. Stroke 2004;35:2764-9.

6. Peterson LR, Waggoner AD, Schechtman KB, Meyer T, Gropler RJ, Barzilai B, et al. Alterations in left ventricular structure and function in young healthy obese women: assessment by echocardiography and tissue Doppler imaging. J Am Coll Cardiol 2004;43:1399-404.

7. Stengel B, Tarver-Carr ME, Powe NR, Eberhardt MS, Brancati FL. Lifestyle factors, obesity and the risk of chronic kidney disease. Epidemiology 2003;14:479-87.

8. Bhaskaran K, Dos-Santos-Silva I, Leon DA, Douglas IJ, Smeeth L. Association of BMI with overall and cause-specific mortality: a population-based cohort study of 3.6 million adults in the UK. Lancet Diabetes Endocrinol 2018;6:944-53.

9. Ricci MA, De Vuono S, Scavizzi M, Gentili A, Lupattelli G. Facing morbid obesity: how to approach it. Angiology. 2016; 67:391-7.

10. Torgerson JS, Hauptman J, Boldrin MN, Sjöström L. XENical in the prevention of diabetes in obese subjects (XENDOS) study: a randomized study of orlistat as an adjunct to lifestyle changes for the prevention of type 2 diabetes in obese patients. 
Diabetes Care 2004;27:155-61.

11. Sjöström L, Lindroos AK, Peltonen M, Torgerson J, Bouchard C, Carlsson B, et al. Lifestyle, diabetes, and cardiovascular risk factors 10 years after bariatric surgery. N Engl J Med 2004; 351:2683-93.

12. Kim BY, Kang SM, Kang JH, Kang SY, Kim KK, Kim KB, et al. 2020 Korean Society for the Study of Obesity Guideline for the Management of Obesity in Korea. J Obes Metab Syndr 2021;30:81-92.
13. Devaux M, Sassi F. Social inequalities in obesity and overweight in 11 OECD countries. Eur J Public Health 2013;23:464-9.

14. Nam GE, Kim YH, Han K, Jung JH, Rhee EJ, Lee SS, et al. Obesity Fact Sheet in Korea, 2019: Prevalence of Obesity and Abdominal Obesity from 2009 to 2018 and Social Factors. J Obes Metab Syndr 2020;29:124-32.

15. Lee HJ, Ahn HS, Choi YB, Han SM, Han SU, Heo YS, et al. Nationwide Survey on bariatric and metabolic surgery in Korea: 2003-2013 results. Obes Surg 2016;26:691-5. 